\title{
The effect of sildenafil on pleural and peritoneal effusions after the TCPC operation
}

\section{Koski, Tapio K.}

2019-11

Koski , T K , Suominen , P K, Raissadati , A , Knihtilä , H M , Ojala , T H \& Salminen , J T 2019 , ' The effect of sildenafil on pleural and peritoneal effusions after the TCPC operation ' , Acta Anaesthesiologica Scandinavica , vol. 63 , no. 10 , pp. 1384-1389 . https://doi.org/10.1111/aas.13431

http://hdl.handle.net/10138/312951

https://doi.org/10.1111/aas.13431

acceptedVersion

Downloaded from Helda, University of Helsinki institutional repository.

This is an electronic reprint of the original article.

This reprint may differ from the original in pagination and typographic detail.

Please cite the original version. 
DR TAPIO KALERVO KOSKI (Orcid ID : 0000-0002-5556-2399)

DR PERTTI K SUOMINEN (Orcid ID : 0000-0002-3365-5965)

Article type : Clinical investigation

The effect of sildenafil on pleural and peritoneal effusions after the TCPC operation

Tapio K Koski ${ }^{1}$

Pertti K Suominen, ${ }^{1, \dagger}$

Alireza Raissadati ${ }^{2,3}$

Hanna M Knihtilä²

Tiina H Ojala ${ }^{2,3}$

Jukka T Salminen ${ }^{4}$

${ }^{1}$ Department of Anesthesia and Intensive Care, Children's Hospital, Helsinki University Hospital, Stenbäckinkatu 11, P.O.B. 281, 00029 HUS, Helsinki, Finland

${ }^{2}$ Faculty of Medicine, University of Helsinki, Haartmaninkatu 8, P.O.B. 63, 00014 University of Helsinki, Helsinki, Finland

${ }^{3}$ Department of Pediatric Cardiology, Children's Hospital, Helsinki University Hospital, Stenbäckinkatu 11, P.O.B. 281, 00029 HUS, Helsinki, Finland

${ }^{4}$ Department of Pediatric Cardiac Surgery, Children's Hospital, Helsinki University Hospital,

This article has been accepted for publication and undergone full peer review but has not been through the copyediting, typesetting, pagination and proofreading process, which may lead to differences between this version and the Version of Record. Please cite this article as doi:

10.1111/aas. 13431

This article is protected by copyright. All rights reserved. 
Stenbäckinkatu 11, P.O.B. 281, 00029 HUS, Helsinki, Finland

${ }^{\dagger}$ Deceased 9 January 2018

Short title: Sildenafil after the TCPC operation

Word count (excl. abstract and references) 3458

Address correspondence to Dr Tapio Koski

Department of Anesthesiology and Intensive Care, Children's Hospital, Helsinki University Hospital, P.O. B. 281, Stenbäckinkatu 11, FI-00029 HUS, Helsinki, Finland, Tel: +358-9-

4711, Fax: +358-9-471 76711, E-mail: tapio.koski@ hus.fi , tapio.koski@ fimnet.fi

Conflict of interest: none

\section{Abstract}

Background: We evaluated whether the administration of sildenafil in children undergoing TCPC operation shortened the interval from the operation to the removal of the pleural and peritoneal drains.

Methods: We retrospectively reviewed the data of 122 patients who had undergone the TCPC operation between 2004 and 2014. Patients were divided into two groups on the basis of their treatments. Sildenafil was orally administered preoperatively in the morning of the procedure or within 24 hours after the TCPC operation to the sildenafil group $(n=48)$, which was compared to a control group $(n=60)$. Fourteen patients were excluded from the study.

Results: The primary outcome measure was time from the operation to the removal of the drains. The study groups had similar demographics. The median [interquartile range] time to removal of drains (sildenafil group 11 [8-19] vs. control group 11 [7-16] days, $\mathrm{P}=0.532$ ) was comparable between the groups. The median [interquartile range] fluid balance on the first postoperative day was significantly higher $(P=0.001)$ in the sildenafil group compared with This article is protected by copyright. All rights reserved. 
controls (47 [12-103] vs. 7 [-6-67] $\mathrm{ml} / \mathrm{kg})$. The first postoperative day fluid balance was a significant predictor for a prolonged need for drains in the multivariate analysis.

Conclusions: Sildenafil administration, preoperatively or within 24 hours after the TCPC operation, did not reduce the required time for pleural and peritoneal drains but was associated with a significantly higher positive fluid balance.

\section{Editorial Comment}

In this very special surgical cohort, children in staged surgical palliative interventions for their congenital univentricular heart malformation, there is a late step with a total cavopulmonary connection. One challenge in this cohort is pleural and peritoneal effusions. In this retrospective analysis, treatment with sildenafil was associated with less time postoperatively where pleural and peritoneal effusions require drainage. We remember our cherished friend and editor for this journal Pertti Suominen, who contributed to this work and is a posthumous author.

\section{Introduction}

The total cavopulmonary connection (TCPC) operation is the last stage in the palliative treatment of patients with a univentricular heart malformation. Prolonged pleural and peritoneal effusion, however, remains a significant source of morbidity after the TCPC operation. ${ }^{1,2}$ High preoperative pulmonary artery pressure is a risk factor for prolonged pleural effusion. ${ }^{3}$ Sildenafil has been used in the treatment of pulmonary hypertension. Sildenafil reduces pulmonary vascular resistance and the transpulmonary gradient, which could, in theory, decrease pleural and peritoneal effusions after the TCPC operation. ${ }^{4}$ Therefore, in 2006, our institution started the administration of sildenafil after the TCPC operation for occasional patients and usually later than 24 hours after operation, and since

This article is protected by copyright. All rights reserved. 
2009 , the majority of the patients received their first dose of sildenafil preoperatively in the morning of the operation. However, the benefits of sildenafil have been controversial in the two recent retrospective Fontan series. ${ }^{5,6}$

Our aim in this study was to analyze the effect of prophylactic sildenafil on pleural and peritoneal effusion during the first postoperative day (POD) after TCPC surgery. We hypothesized that prophylactic sildenafil administration would result in decreased pleural and peritoneal effusions, and earlier removal of drains.

\section{Methods}

This retrospective study was performed in the Children's Hospital of Helsinki University Hospital, which is a tertiary care hospital responsible for the care of all pediatric patients requiring open-heart surgery in Finland. The study was approved by the Ethics Committee (26.3.2015, 84/13/03/2015) and the Research Committee of the Children's Hospital (approval $\S 52 / 9.6 .2015)$.

All patients who underwent primary TCPC surgery between 1.1.2004 and 31.12.2014 were considered for the study. Re-operations were excluded from the dataset. Patients were retrospectively divided into two groups. The sildenafil group comprised all patients who received prophylactic sildenafil either preoperatively in the morning of the procedure or within 24 hours after admission to the pediatric intensive care unit (PICU) $(n=48)$. A total of 60 patients, who did not receive sildenafil served as controls. Patients who were administered sildenafil later than 24 hours after the admission to PICU $(n=14)$ were excluded from the study. Sildenafil was administered to patients according to the clinical judgment of surgeons and anesthesiologists. At that time of the study, no official guidelines for this specific question existed in our institution. The use of sildenafil quickly became a routine treatment in our institution in 2009 because of its theoretical advantages.

This article is protected by copyright. All rights reserved. 


\section{Operative procedure}

The management of anesthesia and cardiac surgery varied little during the study period. Anesthesia was induced with sufentanyl, pancuronium, and propofol and maintained by either propofol-infusion (6-10 $\mathrm{mg} / \mathrm{kg} / \mathrm{h})$ or sevoflurane combined with sufentanyl-infusion (1$2 \mu \mathrm{g} / \mathrm{kg} / \mathrm{h})$.

Blood flow during normothermic cardiopulmonary bypass (CPB) was $2.4 \mathrm{l} / \mathrm{min} / \mathrm{m}^{2}$. Seventytwo operations were performed with aortic cross clamping and thirty-six operations with a beating heart. The pump prime solution consisted of packed red cells, fresh frozen plasma, and albumin. The surgical technique for all the operations was the extracardiac conduit connection between the inferior vena cava and the pulmonary artery. In most patients $(n=101)$ the size of the extracardiac conduit was $18 \mathrm{~mm}$. The decision to perform a fenestration of the TCPC pathway was at the discretion of the surgeon. The hematocrit was adjusted to $30 \%$ and increased during the rewarming by hemofiltration to between $35-40 \%$, and by adding packed red cells as necessary. Continuous hemofiltration was used throughout the CPB when needed.

Inotropic infusions were used to maintain adequate blood pressure and cardiac output. Milrinone was used as a first-line inotropic therapy at a median dose of $0.54 \mu \mathrm{g} / \mathrm{kg} / \mathrm{min}$, whereas epinephrine or norepinephrine were used on an as-needed basis. There was no single standard blood pressure goal in our institution. A mean arterial pressure of $50 \mathrm{mmHg}$ was mostly used as a cut-off for 3-4-year-old patients. The vasoactive-inotropic score was calculated according to Gaies et al. ${ }^{7}$

This article is protected by copyright. All rights reserved. 


\section{Postoperative care}

Anesthesiologists were in charge of the treatments in the PICU. Cardiac surgeons and cardiologists were also actively involved in postoperative care as consultants. The treatment of hemorrhage and blood product administration was managed according to existing protocols with individual considerations. The limit for red blood cell transfusion was a hemoglobin level of $120 \mathrm{~g} / \mathrm{L}$. All patients were extubated in the PICU after warming, arousal from general anesthesia, hemodynamic stabilization and confirmation of minimal bleeding. Inhaled nitric oxide (iNO) was started in the operating room or the PICU at the discretion of the surgeon and the anesthesiologist in charge of the patient. All patients received furosemide, and most patients $(n=87)$ received spironolactone. Patients were discharged to the cardiac ward after achieving adequate gas exchange, stable hemodynamics and without the need for other inotropes than milrinone.

A single drain was removed in the ward if the effusion was insignificant. All the remaining drains were removed when the total pleural and peritoneal effusions reached less than $3 \mathrm{ml} / \mathrm{kg} /$ day. Drains were replaced according to clinical consideration in cases of symptomatic fluid accumulation.

\section{Data collection}

The primary outcome measure was the time to removal of drains, and the secondary outcome measures were the pleural and peritoneal effusions during the first POD and length of hospital and PICU stay. Multiple regression analysis was used to identify risk factors for prolonged effusion.

This article is protected by copyright. All rights reserved. 
Perioperative data were manually collected from the anesthesia records and our institutional intensive care database (Centricity Critical Care Clinisoft; GE Healthcare, Chicago, Illinois, U.S.). Postoperative data was manually collected from both paper and electronic patient records in Helsinki University Hospital. Data from preoperative cardiac catheterizations performed during the preceding 6 months were also collected. Cardiac catheterization pressures were registered in the patient records at $1 \mathrm{mmHg}$ accuracy.

All deaths within 30 days of the operation were categorized as early deaths. For survival analyses, the last day of follow-up was 18.3.2016. End-points were death or heart transplantation. The date of death or transplantation was obtained from patient records, our national cardiac surgery database ProCardio, and the Finnish National Registry. All operations and follow-up were carried out at Helsinki Children's Hospital, with a follow-up of $100 \%$.

\section{Statistical analyses}

Data are presented as $\mathrm{n}(\%)$ for categorical data, mean \pm standard deviation (SD) or median interquartile range (IQR) for continuous data. Normal distribution was tested using ShapiroWilk test. The Mann-Whitney-U test was used for comparing distributions of two groups. Pvalues of less than 0.05 were considered statistically significant. Multiple regression analysis was used for multivariable analysis. All statistical analyses were performed using SPSS Statistics (version 19.0, IBM Corp, Armonk, NY, U.S.).

Results

In total, 122 patients who underwent the TCPC operation between $2004-2014$ were considered for the study. Follow-up was complete (100\%) for all patients. Forty-eight patients (39\%) received sildenafil either preoperatively or within 24 hours of their admission to the PICU, and 60 patients (49\%) did not receive sildenafil at any stage. Fourteen (11\%) patients

This article is protected by copyright. All rights reserved. 
who received sildenafil more than 24 hours from PICU admission were excluded from the study. 47 patients (78\%) of the control group were operated before 31.7.2007. Until that, not a single patient of the sildenafil group was operated. Respectively 40 patients (83\%) of the sildenafil group were operated after 1.5.2009, and not a single patient operated after that belonged to the control group. Approximately $20 \%$ of the patients were operated between 1.8.2007-30.4.2009, at that time sildenafil quickly became a routine treatment. The median age of the 108 children who were included in the study was 3.2 [2.9-3.6] years. Mean sildenafil starting dose was $3.4 \pm 1.2 \mathrm{mg} / \mathrm{kg} / \mathrm{day}$ and it was continued at least until discharge from the hospital. For at least 33 patients of the sildenafil group, sildenafil was continued after discharge. Most baseline characteristics were comparable between the groups, including operative weight, preoperative mean pulmonary artery pressure (mPAP), oxygen saturation and the percentage of fenestrated TCPC operations (Table 1). Age $(P=0.013)$ and preoperative transpulmonary gradient $(P=0.004)$ were higher in the control group. No patients died within 30 days from the operation. Two patients, who did not receive sildenafil pre- or postoperatively died within a year of their operation $(P=0.149)$. No patients required heart transplantation within the first postoperative year.

All patients had pleural drains, and 80 out of 108 patients had an ascites drain. The median amount of first-day pleural and peritoneal effusion was $78.8 \mathrm{ml} / \mathrm{kg} /$ day. The median time to removal of drains did not differ significantly between the sildenafil and control group (11 [8$19]$ vs. 11 [7-16] days respectively, $P=0.532)$. The relative amount of pleural and peritoneal effusion on the first POD and the length of stay in the PICU and hospital were also similar (Table 2). However, the median fluid balance on the first POD was significantly higher in the sildenafil group compared with controls (47 [12-103] vs. $7[-6-67] \mathrm{ml} / \mathrm{kg}, \mathrm{P}=0.001)$.

This article is protected by copyright. All rights reserved. 
We performed multiple regression analysis to recognize the potential predictors of a prolonged need for pleural drains. Variables included in the multivariable analysis were decided according to clinical reasoning and listed in Table 3. The first-day fluid balance in the PICU (95\% confidence interval $(\mathrm{Cl})$ 0.015-0.094, $\mathrm{P}=0.007$; Table 3$)$ and the use of iNO during the first POD $(95 \% \mathrm{Cl}, 0.206-11.466, \mathrm{P}=0.042)$ were the only significant predictors of time from the operation to the removal of drains (Table 3). Patients who received iNO during the first POD produced larger amounts of effusions during the first POD, but they also had a longer duration of CPB $(P=0.014)$ and higher vasoactive-inotropic scores $(P<0.001)$ and serum lactate on admission to PICU $(P=0.026)$ even before the iNO was started.

\section{Discussion}

Sildenafil administration preoperatively or within 24 hours after a TCPC operation was associated with a significantly more positive fluid balance but did not shorten the time from the operation to the removal of the drains.

Earlier studies on the effect of sildenafil have reported controversial findings. A retrospective study by Giordano et al. reported that sildenafil significantly reduced ascites and pleural fluid effusion, the need for vasoactive drugs, and shortened mechanical ventilation time. ${ }^{5}$ In contrast, a study by Mendoza et al. found that sildenafil and inhaled nitric oxide did not influence the duration of pleural effusion, mechanical ventilation, or the lengths of PICU or hospital stay. ${ }^{6}$ Sildenafil reduced pulmonary vascular resistance, but it also increased systemic vasodilatation, which may increase the need for postoperative fluid resuscitation.

This article is protected by copyright. All rights reserved. 
In the current study, the first POD fluid balance in PICU and the use of iNO were the only factors associated with a significantly longer need for drains in the multivariable analyses. Patients administered iNO were sicker which prevents us from making any conclusions of the effect of iNO on outcomes. Previous studies reported that high intravenous fluid requirement during the first 24 postoperative hours after the TCPC procedure was an independent risk factor for increased pleural effusion and prolonged recovery. ${ }^{8,9}$ Excessive fluid resuscitation may damage the endothelial glycocalyx ${ }^{10}$ and thus increase vascular permeability and prolong the need for drains. Recently published TCPC management protocols such as the Portland and the Wisconsin protocols suggest that high dose diuretics prevent fluid accumulation. In these protocols supplemental oxygen is recommended for reducing pulmonary vascular resistance and sildenafil is not included. ${ }^{11-13}$

Early extubation after the TCPC procedure has been associated with improved hemodynamics and shorter time to chest tube removal as the negative inspiratory intrathoracic pressure enhances pulmonary venous return. ${ }^{14,15}$ In the study by Giordano et al. mechanical ventilation times shortened simultaneously with the introduction of the new protocol and the use of sildenafil when compared to historical controls. The mean intubation time in the sildenafil group was $15.5 \pm 4$ hours and $23.3 \pm 6$ hours in the historical control group. ${ }^{5}$ Whether earlier extubation was due to the use of sildenafil or the awareness of the benefits of early extubation remains a question. Subsequent studies have not been able to reproduce these outcomes. ${ }^{6}$ In our study, the mean intubation time in the sildenafil group (19.6 \pm 31.9 hours) and the control group (19.0 \pm 27.0 hours) were both comparable with the control group of Giordano's study. However, the effect of sildenafil on mechanical ventilation time is difficult to determine due to the presence of multiple confounding factors such as ventilator weaning protocols and PICU workload that might affect the extubation time.

This article is protected by copyright. All rights reserved. 
Intravenous sildenafil reduced pulmonary artery pressure by about $10 \%$ in infants undergoing cardiac surgery with slightly elevated pulmonary artery pressures. ${ }^{16}$ Also, sildenafil significantly reduced systemic blood pressure with systemic vasodilatation and deterioration in oxygenation, which was not improved by the administration of iNO. The deterioration in oxygenation most likely occurred due to an increase in intrapulmonary shunting due to sildenafil administration. ${ }^{16}$ There was no difference in the postoperative arterial saturation, central venous saturation, or lactate values between the groups in our data.

In the present study milrinone, an ino-vasodilator, was used as first-line inotropic therapy for all the patients. Moreover, iNO was administered significantly more often to the sildenafil group than the control group. This effective reduction in the systemic vascular resistance and blood pressure after the TCPC operation was related to a significantly higher inotropic score on arrival at the PICU. It was also associated with increased fluid resuscitation leading to a significantly more positive fluid balance during the first and second POD. This combination therapy outweighed the possible beneficial effects of reduced normal pulmonary artery pressure to enhance pulmonary blood flow in patients after the TCPC operation. Liberal fluid administration associates with sildenafil, but the causal connection remains a question this study cannot answer. Many of the patients who received iNO also had substantial effusions and were hemodynamically unstable when placed on iNO. The significantly lower postoperative furosemide dose in the sildenafil group compared with the control group may be related to low blood pressure and the consequent decision to withhold the furosemide administration, although postoperatively blood pressure data were not collected in this study.

This article is protected by copyright. All rights reserved. 
This was a pilot study to evaluate the effect of sildenafil on pleural effusion. TCPC protocols such as Portland or Wisconsin protocols that use fluid restriction without sildenafil seem to be rational. ${ }^{11-13}$ The next step would be to implement a similar protocol including early extubation within 6 hours ${ }^{14,15}$ in our institution and to collect data prospectively to detect the possible improvements in the outcome of this patient group.

\section{Limitations}

This study is a retrospective single center study and thus should be interpreted carefully. The study population was small, which reduces the statistical power of the study. However, the present study is larger than previous studies on sildenafil after the TCPC operation. Fourteen patients were excluded from the study because they didn't match the definitions of either the control or sildenafil group. These patients received sildenafil later during their hospital stay when effusions had already increased. Patients in the sildenafil group were slightly younger because the control group included some patients on whom TCPC surgery was performed at an older age. Data on the daily drainage amounts or fluid resuscitation for the whole hospital period could not be obtained for a small portion of the patients that underwent the TCPC operation. Daily albumin levels were not measured systematically. For completeness and comparison of follow-up data, we had to use the length of time to the removal of the drains. About $20 \%$ of patients in both groups were operated during the same era which makes these patients susceptible to selection bias.

\section{Conclusions}

Oral sildenafil administration preoperatively or within 24 hours after the TCPC operation had no positive effect on the clinical outcome.

This article is protected by copyright. All rights reserved. 


\section{Acknowledgments}

This article is dedicated to the memory of Dr. Pertti Suominen. We thank him for all his contributions to the medical and scientific field.

\section{Funding}

The consultation fees concerning statistical analysis and language review were funded by the Children's Hospital.

Helsingin ja Uudenmaan Sairaanhoitopiiri : Language and statistical consultation fees

\section{Conflict of interest}

The authors have no conflicts of interest

\section{References}

1. Mascio CE, Austin EH. Pleural effusions following the Fontan procedure. Curr Opin Pulm Med. 2010;16:362-366.

2. Sasaki J, Dykes JC, Sosa LJ, Salvaggio JL, Tablante MD, Ojito J, Khan DM, Hannan RL, Rossi AF, Burke RP, Wernovsky G. Risk Factors for Longer Hospital Stay Following the Fontan Operation. Pediatr Crit Care Med. 2016;17:411-419.

3. Mascio CE, Wayment M, Colaizy TT, Mahoney LT, Burkhart HM. The modified fontan procedure and prolonged pleural effusions. Am Surg. 2009;75:175-177.

4. Tunks RD, Barker PC a, Benjamin DK, et al. Sildenafil Exposure and Hemodynamic Effect After Fontan Surgery. Pediatr Crit Care Med. 2014;15:28-34.

5. Giordano R, Palma G, Poli V, Palumbo S, Russolillo V, Cioffi S, Mucerino M,

This article is protected by copyright. All rights reserved. 
Mannacio VA, Vosa C. First experience with sildenafil after Fontan operation: shortterm outcomes. J Cardiovasc Med 2015;16:552-555.

6. Mendoza A, Albert L, Belda S, Casanueva L, Herrera D, Granados MA, Velasco JM, García E, Aguilar JM, Comas JV. Pulmonary vasodilator therapy and early postoperative outcome after modified Fontan operation. Cardiol Young. $2015 ; 25: 1136-1140$.

7. Gaies MG, Jeffries HE, Niebler RA, Pasquali SK, Donohue JE, Yu S, Gall C, Rice TB, Thiagarajan RR. Vasoactive-Inotropic Score Is Associated With Outcome After Infant Cardiac Surgery. Pediatr Crit Care Med. 2014;15(6):529-537.

8. Salvin JW, Scheurer MA, Laussen PC, Mayer JE, del Nido PJ, Pigula FA, Bacha EA, Thiagarajan RR. Factors Associated With Prolonged Recovery After the Fontan Operation. Circulation 2008;118:S171-176.

9. Zaccagni HJ, Alten JA, Cleveland DC, Argent RT, Law MA, Bryant AS, Borasino S. Early Postoperative Albumin Administration Contributes to Morbidity After the Fontan Operation. Pediatr Cardiol. 2016;37:1278-1283

10. Chappell D, Bruegger D, Potzel J, Jacob M, Brettner F, Vogeser M, Conzen P, Becker BF, Rehm M. Hypervolemia increases release of atrial natriuretic peptide and shedding of the endothelial glycocalyx. Crit Care 2014;18:538.

11. Pike NA, Okuhara CA, Toyama J, Gross BP, Wells WJ, Starnes VA. Reduced pleural drainage, length of stay, and readmissions using a modified Fontan management protocol. J Thorac Cardiovasc Surg. 2015;150(3):481-487.

12. Sunstrom RE, Muralidaran A, Gerrah R, Reed RD, Good MK, Armsby LR, Rekito AJ, Zubair MM, Langley SM. A defined management strategy improves early outcomes after the fontan procedure: the portland protocol. Ann Thorac Surg. 2015;99(1):148155.

This article is protected by copyright. All rights reserved. 
13. Cava JR, Bevandic SM, Steltzer MM, Tweddell JS. A medical strategy to reduce persistent chest tube drainage after the fontan operation. Am J Cardiol. 2005;96(1):130-133.

14. Mutsuga M, Quiñonez LG, Mackie AS, Norris CM, Marchak BE, Rutledge JM, Rebeyka IM, Ross DB. Fast-track extubation after modified Fontan procedure. J Thorac Cardiovasc Surg. 2012;144(3):547-552.

15. Morales DLS, Carberry KE, Heinle JS, McKenzie ED, Fraser CD, Diaz LK. Extubation in the Operating Room After Fontan's Procedure: Effect on Practice and Outcomes. Ann Thorac Surg. 2008;86(2):576-581.

16. Stocker C, Penny DJ, Brizard CP, Cochrane AD, Soto R, Shekerdemian LS. Intravenous sildenafil and inhaled nitric oxide: a randomised trial in infants after cardiac surgery. Intensive Care Med. 2003;29(11):1996-2003.

This article is protected by copyright. All rights reserved. 
Table 1. Demographic and preoperative data

\begin{tabular}{|llll|}
\hline & $\begin{array}{l}\text { Sildenafil } \\
\text { group } \\
\mathrm{N}=48\end{array}$ & $\begin{array}{l}\text { Control } \\
\text { group } \\
\mathrm{N}=60\end{array}$ & P-value \\
& $3.3[2.9-3.8]$ & $3.0[2.7-3.5]$ & $0.013^{\mathrm{a}}$ \\
\hline Age (years) & $24(50 \%)$ & $39(65 \%)$ & $0.118^{\mathrm{a}}$ \\
\hline Sex (male) & $14.5[13.0-$ & $13.9[12.6-$ & $0.395^{\mathrm{a}}$ \\
\hline Weight (kg) & $15.6]$ & $15.3]$ & \\
& $0.61[0.57-$ & $0.59[0.56-$ & $0.149^{\mathrm{a}}$ \\
& $0.65]$ & $0.63]$ & \\
\hline Body surface area $\left(\mathrm{m}^{2}\right)$ & $169[163-178]$ & $171[164-$ & $0.573^{\mathrm{a}}$ \\
& & $178]$ & \\
\hline Hemoglobin (g/l) & & & $0.897^{\mathrm{a}}$ \\
& $27(56 \%)$ & $33(55 \%)$ & $0.593^{\mathrm{a}}$ \\
\hline Main cardiac defect & $16(33 \%)$ & $23(38 \%)$ & $0.744^{\mathrm{a}}$ \\
\hline HLHS n (\%) & $4(8 \%)$ & $4(7 \%)$ & $0.264^{\mathrm{a}}$ \\
\hline RV-hypoplasia & $1(2 \%)$ & $0(0 \%)$ & $0.792^{\mathrm{a}}$ \\
\hline Unbalanced AVSD & $16(33 \%)$ & $24(40 \%)$ & $0.543^{\mathrm{a}}$ \\
\hline Other UVH & $10.5[9.5-$ & $11.0[9.5-$ & \\
\hline Systemic ventricle $(\mathrm{LV})$ & $11.5]$ & $11.5]$ & $0.818^{\mathrm{a}}$ \\
\hline mPAP (mmHg) & $83[80-86]$ & $83[80-86]$ & $0.004^{\mathrm{a}}$ \\
\hline SaO2 (\%) & $4[3.5-5]$ & $5[4-6]$ & $0.624^{\mathrm{a}}$ \\
\hline Transpulmonary gradient $(\mathrm{mmHg})$ & $6[4-8]$ & $6[5-7]$ & \\
\hline End diastolic pressure $(\mathrm{mmHg})$ & &
\end{tabular}

Data are presented as the number of subjects (\%), median [interquartile range]

${ }^{a}$ Mann-Whitney-U test

Abbreviations: AVSD, atrioventricular septal defect; HLHS, hypoplastic left heart syndrome;

LV, left ventricle; mPAP, mean pulmonary artery pressure; RV-hypoplasia, hypoplasia of right ventricle; $\mathrm{SaO} 2$, arterial oxygen saturation; UVH, univentricular heart.

This article is protected by copyright. All rights reserved. 
Table 2. Procedural and postoperative data

\begin{tabular}{|c|c|c|c|}
\hline & $\begin{array}{l}\text { Sildenafil group } \\
(\mathrm{N}=48)\end{array}$ & $\begin{array}{l}\text { Control group } \\
(\mathrm{N}=60)\end{array}$ & P-value \\
\hline Operation with fenestration & $38(83 \%)$ & $54(90 \%)$ & $0.107^{\mathrm{a}}$ \\
\hline CPB time (min) & $92[66-121]$ & $77[55-115]$ & $0.181^{a}$ \\
\hline $\begin{array}{l}\text { Operation with aortic cross } \\
\text { clamping }\end{array}$ & $35(73 \%)$ & $37(62 \%)$ & $0.220^{\mathrm{a}}$ \\
\hline Aortic cross clamping time (min) & $35[17-56]$ & 51 [22-67] & $0.188^{\mathrm{a}}$ \\
\hline \multicolumn{4}{|l|}{ On the PICU admission } \\
\hline Vasoactive-inotropic-score & 25 [18-32] & $17[12-24]$ & $<0.001^{a *}$ \\
\hline Central venous saturation (\%) & 67 [60-74] & 64 [59-73] & $0.421^{\mathrm{a}}$ \\
\hline Lactate $(\mathrm{mmol} / \mathrm{l})$ & $1.7[1.2-2.0]$ & $1.2[1.0-1.6]$ & $0.001^{a}$ \\
\hline \multicolumn{4}{|l|}{ On the first POD at noon } \\
\hline Vasoactive-inotropic score & $10[5-18]$ & $9[6-17]$ & $0.829^{a}$ \\
\hline Central venous saturation (\%) & $69[61-76]$ & $69[61-74]$ & $0.890^{a}$ \\
\hline $\mathrm{SaO} 2(\%)$ & $90[86-94]$ & $91[87-96]$ & $0.319^{a}$ \\
\hline Lactate $(\mathrm{mmol} / \mathrm{l})$ & $2.0[1.6-2.5]$ & $2.1[1.6-2.6]$ & $0.620^{a}$ \\
\hline Hemoglobin $(\mathrm{g} / \mathrm{l})$ & $147[139-162]$ & $153[141-164]$ & $0.290^{\mathrm{a}}$ \\
\hline$\Delta$ hemoglobin $(\mathrm{g} / \mathrm{l})$ & $-22.7 \pm 15.7$ & $-19.8 \pm 18.9$ & $0.209^{a}$ \\
\hline iNO during first $24 \mathrm{~h}$ & $41(89 \%)$ & $36(60 \%)$ & $0.002^{a}$ \\
\hline $\begin{array}{l}\text { Ascites drainage loss in } 0-24 \mathrm{~h} \\
\text { (ml/kg/day) }\end{array}$ & $23[0-45]$ & $44[1-80]$ & $0.047^{a}$ \\
\hline $\begin{array}{l}\text { Pleural and mediastinal drainage } \\
\text { loss in } 0-24 \mathrm{~h}(\mathrm{ml} / \mathrm{kg} / \text { day })\end{array}$ & 45 [33-70] & 43 [33-52] & $0.141^{a}$ \\
\hline $\begin{array}{l}\text { Total drainage loss in } 0-24 \mathrm{~h} \\
\text { (ml/kg/day) }\end{array}$ & 76 [45-122] & $80[53-132]$ & $0.400^{\mathrm{a}}$ \\
\hline $\begin{array}{l}\text { Fluid balance } 24 \mathrm{~h} \text { after operation } \\
(\mathrm{ml} / \mathrm{kg})\end{array}$ & $47[12-103]$ & $7[-6-67]$ & $0.001^{a}$ \\
\hline $\begin{array}{l}\text { Ascites drainage loss in } 24-48 \mathrm{~h} \\
\text { (ml/kg/day) }\end{array}$ & $8.6[0-19]$ & $11[0-24]$ & $0.566^{a}$ \\
\hline $\begin{array}{l}\text { Pleural and mediastinal drainage } \\
\text { loss in } 24-48 \mathrm{~h}(\mathrm{ml} / \mathrm{kg} / \text { day })\end{array}$ & 34 [23-49] & 26 [19-48] & $0.156^{\mathrm{a}}$ \\
\hline $\begin{array}{l}\text { Total drainage loss in } 24-48 \mathrm{~h} \\
(\mathrm{ml} / \mathrm{kg} / \mathrm{day})\end{array}$ & 47 [30-60] & $43[21-57]$ & $0.496^{a}$ \\
\hline $\begin{array}{l}\text { Fluid balance (cumulative in first } 48 \\
\text { h) }(\mathrm{ml} / \mathrm{kg})\end{array}$ & $24[-7-80]$ & $-12[-47-14]$ & $<0.001^{a *}$ \\
\hline $\begin{array}{l}\text { Creatinine } 48-72 \mathrm{~h} \text { after operation } \\
(\mu \mathrm{mol} / \mathrm{l})\end{array}$ & 26 [23-30] & 28 [25-36] & $0.038^{a}$ \\
\hline Furosemide first POD $(\mathrm{mg} / \mathrm{kg})$ & $0.72[0.53-1.0]$ & $1.1[0.74-1.6]$ & $<0.001^{a *}$ \\
\hline Spironolactone first POD $(\mathrm{mg} / \mathrm{kg})$ & $1.9[1.0-2.1]$ & $1.6[0.8-2.0]$ & $0.306^{a}$ \\
\hline Drain removal (days) & $11[8-19]$ & $11[7-16]$ & $0.532^{\mathrm{a}}$ \\
\hline Intubation time (hours) & $9.6[5.5-20.4]$ & $8.1[5.5-19.3]$ & $0.889^{a}$ \\
\hline PICU stay (days) & $4[3-5]$ & $4[3-5]$ & $0.578^{a}$ \\
\hline Hospital stay (days) & $17[14-26]$ & $16[12-21]$ & $0.323^{a}$ \\
\hline Mortality (30 days) & 0 & & \\
\hline
\end{tabular}

Data are presented as the number of subjects (\%), mean \pm standard deviation or median

[interquartile range]

${ }^{a}$ Mann-Whitney-U test

This article is protected by copyright. All rights reserved. 
* P-value rounded up

Abbreviations: CPB, cardiopulmonary bypass; $\Delta$ hemoglobin, the difference between hemoglobin on the first POD and preoperative; iNO, inhaled nitric oxide; PICU, pediatric intensive care unit; $\mathrm{POD}$, postoperative day; $\mathrm{SaO} 2$, arterial oxygen saturation.

Table 3 Multiple regression analysis for the time of drains

\begin{tabular}{|llll|}
\hline & $\mathrm{P}$ & $95 \% \mathrm{Cl}$ & $\beta$ \\
\hline Systemic ventricle (LV) & 0.144 & $-8.208-1.224$ & -0.172 \\
\hline mPAP preoperatively & 0.807 & $-1.239-0.968$ & -0.027 \\
\hline Fenestration & 0.836 & $-6.143-7.577$ & 0.024 \\
\hline Cardiopulmonary bypass time & 0.768 & $-0.066-0.049$ & -0.033 \\
\hline Sildenafil & 0.283 & $-7.270-2.154$ & -0.129 \\
\hline Hemoglobin on first POD & 0.181 & $-0.042-0.220$ & 0.144 \\
\hline Mechanical ventilation time in PICU & 0.932 & $-2.208-2.025$ & -0.011 \\
\hline iNO during first 24h & 0.042 & $0.206-11.466$ & 0.243 \\
\hline Fluid balance first 24h & 0.007 & $0.015-0.094$ & 0.368 \\
\hline Vasoactive-inotropic score on first POD & 0.351 & $-0.434-0.156$ & -0.141 \\
\hline
\end{tabular}

$\mathrm{Cl}$, confidence interval

$\beta$, standardized coefficients

Abbreviations: iNO, inhaled nitric oxide; LV, left ventricle; mPAP, mean pulmonary artery pressure; PICU, pediatric intensive care unit; POD, postoperative day.

This article is protected by copyright. All rights reserved. 